\title{
Paulo Freire na América Latina e nos Estados Unidos: Cátedras e Grupos de Pesquisas
}

\author{
Ivanilde Apoluceno de Oliveira \\ Tânia Regina Lobato dos Santos \\ Universidade do Estado do Pará
}

\section{Resumo}

objetivo deste artigo é apresentar o mapeamento de Institutos, Cátedras, Grupos de pesquisas, com aportes freireanos, na América Latina e nos Estados Unidos, visando identificar que atividades acadêmicas realizam e como se constituem em legado da educação de Paulo Freire. Este estudo é recorte de uma pesquisa empírica, de abordagem qualitativa, sobre a presença de Paulo Freire no contexto educacional da América Latina e nos Estados Unidos, concluída, em 2016, e financiada pelo CNPq. Para este artigo, alguns dados foram atualizados em 2017. Os procedimentos utilizados na pesquisa foram: revisão bibliográfica, pesquisas on-line, visita a universidades via website, contactos via e-mail e entrevista aberta com professores freireanos, participação em eventos, com registro sobre as Cátedras Paulo Freire. Na sistematização dos dados, foram utilizados: quadros com o uso da tabela excele, para a análise, foram criadas categorias temáticas.

Palavras-chave: Paulo Freire. Cátedras e Grupos de Pesquisas. América Latina e Estados Unidos.

\section{Paulo Freire in Latin America and the United States: Chairs and Research Groups}

\section{Abstract}

The objective of this paper is to present the mapping of Institutes, Chairs and Research Groups with contributions of Paulo Freire's thoughts, in both Latin America and the United States, in order to identify which academic activities they perform and how they constitute the legacy of Paulo Freire's education. This study is a summary of an empirical, qualitative approach on the presence of Paulo Freire in the educational context of Latin America and the United States completed in 2016 and funded by CNPq. For this paper, some data were updated in 2017. The procedures used in the research were: bibliographic review, online surveys, visits to universities' websites, e-mail contacts and open interviews with Freirean professors, participation in events with registration about Paulo Freire Chairs. In the data systematization, tables with excel spreadsheet were used, and, for the analysis, thematic categories were created.

Keywords: Paulo Freire. Chairs and Research Groups. Latin America and United States. 


\section{Paulo Freire en América Latina y Estados Unidos: Cátedras y Grupos de Investigación}

\section{Resumen}

El objetivo de este artículo es presentar el mapeamiento de institutos, cátedras, grupos de investigación, con aportes freireanos, en América Latina y los Estados Unidos, buscando identificar qué actividades académicas logran y cómo se constituyen en el legado de la educación de Paulo Freire. Este estudio es un recorte de una investigación empírica, de abordaje cualitativo, sobre la presencia de Paulo Freire en el contexto educativo de América Latina y los Estados Unidos, concluido en 2016 y financiado por CNPq. Para este artículo, algunos datos fueron actualizados en 2017. Los procedimientos utilizados en la investigación fueron: revisión bibliográfica, encuestas en línea, visita a universidades vía web, contactos vía correo electrónico y entrevistas abiertas con profesores freireanos, participación en eventos, con registro sobre las cátedras Paulo Freire. En la sistematización de los datos, fueron utilizados: cuadros con el uso de la tabla de Excel y, para el análisis, se crearon categorías temáticas.

Palabras clave: Paulo Freire. Cátedras e Grupos de investigación. América Latina e Estados Unidos.

\section{Introdução}

O legado de Paulo Freire inicia com a construção teórico-metodológica da educação popular e da educação de jovens e adultos, em articulação com os Movimentos Sociais, nos anos 50 e 60 do Séc. XX. Atravessa nos anos de 1980, com o debate sobre as tendências pedagógicas nos cursos de Pedagogia, sendo considerada a sua Pedagogia Humanista - Libertadora. Nos anos 1990, teve forte influência nas escolas das redes de ensino, por meio de políiticas educacionais. Nos dias atuais, a educação de Paulo Freire vem sendo campo de estudo realizado por pesquisadores em Grupos de Pesquisas, Centros de Investigações, Institutos e Cátedras Paulo Freire, instituídos em diversos países na América Latina, Estados Unidos, Europa, África, entre outros, que evidenciam a existência de um legado de Paulo Freire e a importância de estudos sobre a sua obra e de experiências educacionais de base freireana.

Este estudo é recorte de uma pesquisa empírica, de abordagem qualitativa, sobre a presença de Paulo Freire no contexto educacional da América Latina e nos Estados Unidos, concluída em 2016 e financiada pelo CNPq. Para este artigo, alguns dados foram atualizados em 2017. 
Os procedimentos utilizados na pesquisa foram: revisão bibliográfica, pesquisas on-line, visita a universidades via website, contactos via e-mail com professores atuantes na perpectiva freireana, participação em eventos, com registro sobre as Cátedras Paulo Freire e entrevista aberta com pessoas que viabilizaram o mapeamento dos estudos e práticas educacionais pautadas no referencial teórico-metodológico freireano na América Latina e nos Estados Unidos.

Neste texto, o objetivo é apresentar o mapeamento de Institutos, Cátedras, Grupos de pesquisas, com aportes freireanos, na América Latina e nos Estados Unidos, visando identificar que atividades acadêmicas realizam em termos de pesquisa, formação, eventos, publicações e práticas educacionais e como se constituem em legado da educação de Paulo Freire.

O levantamento das Cátedras e Institutos na Internet foi feito utilizando-se os descritores: "Instituto Paulo Freire", "Cátedra Paulo Freire", acrescidos de: América Latina, Brasil, Chile, Argentina, Colômbia, México, Costa Rica, Cuba, entre outros. Utilizaram-se, também, links de Institutos e Cátedras já encontradas e visitadas na internet.

No levantamento dos Grupos no Diretório do CNPq, foi estabelecido o descritor "Paulo Freire" que deveria estar mencionado no nome do grupo, nas linhas de pesquisas e nas palavras-chaves. Os grupos que mencionaram, explicitamente, o Paulo Freire ou que estava subtendida a presença de Freire foram considerados como referência de estudo.

Na sistematização dos dados, foram utilizados: quadros com o uso da tabela excele, para a análise, foram criadas categorias temáticas.

As categorias temáticas são definidas por Oliveira e Mota Neto (201 1, p. 164) como indicadores de análise, ou seja, "[...] fatores, aspectos, elementos do fato ou situação em estudo, que são classificados e reunidos em eixos ou unidades temáticas a partir e com os dados coletados". Essas categorias temáticas são utilizadas para facilitar a organização dos dados.

Assim, as duas principais categorias temáticas elaboradas no artigo foram: (1) Institutos, Grupos e Cátedras Paulo Freire na América Latina e (2) Institutos, Grupos e Cátedras Paulo Freire nos Estados Unidos.

Apresenta-se, inicialmente, o mapeamento de Institutos, Grupos e Cátedras Paulo Freire na América Latina e, posteriormente, nos Estados Unidos. 


\section{Institutos/grupos/cátedras Paulo Freire na América Latina}

No total, foram encontrados 84 registros de estudos/ações educacionais de Paulo Freire na América Latina, em 11 países, sendo o maior número de registros no Brasil, seguida da Argentina, Colômbia, México e Chile (Quadro 1).

\section{Quadro 1}

Países da América Latina com estudos/ações educacionais de Paulo Freire.

\begin{tabular}{|c|c|}
\hline Países & Quantidade \\
\hline Brasil & 55 \\
\hline Argentina & 09 \\
\hline Colômbia & 05 \\
\hline México & 03 \\
\hline Chile & 03 \\
\hline Cuba & 01 \\
\hline Venezuela & 02 \\
\hline Nicarágua & 01 \\
\hline Peru & 02 \\
\hline Porto Rico & 01 \\
\hline Costa Rica & 02 \\
\hline Total & 84 \\
\hline
\end{tabular}

Fontes: Sites e diretório do CNPq (201 1; 2014; 2017).

Brasil é o que possui maior número de estudos/ações educacionais com base em Paulo Freire, considerando os grupos de pesquisas cadastrados no CNPq, bem como a importância do seu trabalho educacional no Brasil, no âmbito da educação popular, de jovens e adultos, nos movimentos sociais, no campo da pedagogia, nas práticas institucionais, entre outros.

$\bigcirc$ pensamento educacional de Paulo Freire apresenta um paradigma diferenciado de educação, comprometido politicamente com as classes populares, contribuindo para o processo de inclusão social de diversos segmentos sociais, bem como a construção de práticas em ambientes escolares e não 
Paulo Freire na América Latina e nos Estados Unidos: vátedras e grupos de pesquisas

escolares. É destacado por Peter MacLaren como de suma importância para o quadro sociopolítico atual.

A Pedagogia de Paulo Freire é de suma importância para se revisitar, construir e reinventar no âmbito da especificidade contextual do quadro sociopolíitico dos dias de hoje, com suas traumatizantes desigualdades. Como Freire, precisamos devolver à libertação o lugar que verdadeiramente the cabe, como o projeto central da educação (McLAREN, 2001, p. 196).

Há presença significativa de Paulo Freire nos países da América Latina, principalmente em termos Cátedras e Institutos Paulo Freire. $\bigcirc$ Brasil possui 08 (oito) Cátedras e 01 (um) Instituto; a Argentina 04 (quatro) Cátedras e 04 (quatro) Institutos; a Venezuela 01 (uma) Cátedra e 01 (um Instituto); a Colômbia 04 (quatro) Cátedras; o México 03 (três) Cátedras; a Costa Rica 02 (duas); o Peru 01 (um) Instituto e Cuba e Porto Rico apenas 01 (uma) Cátedra. Encontrou-se, também, uma Universidade Paulo Freire na Nicarágua (Quadro 2).

\section{Quadro 2}

Cátedras. Institutos, Grupos de Pesquisas e Universidade Paulo Freire por país da América Latina

\begin{tabular}{|c|c|c|c|c|}
\hline Países & Cátedras & Institutos & Universidade & Grupos/Redes de Pesquisas \\
\hline Brasil & 08 & 01 & - & 46 \\
\hline México & 03 & - & - & - \\
\hline Argentina & 04 & 04 & - & 01 \\
\hline Costa Rica & 02 & - & - & - \\
\hline Colômbia & 04 & - & - & 01 \\
\hline Cuba & 01 & - & - & - \\
\hline Venezuela & 01 & 01 & - & - \\
\hline Porto Rico & 01 & & & 03 \\
\hline Chile & - & - & - & - \\
\hline Nicarágua & - & - & 01 & 01 \\
\hline Peru & & 01 & - & 52 \\
\hline Total =84 & 24 & 07 & 01 & $0 \times 120141$ \\
\hline
\end{tabular}

Fonte: Mafra e Gadotti (2005), sites (2014; 2015; 2017$)$ e Diretório do CNPq (2014). 
No Brasil, as Cátedras mais recentes são: Cátedra do Oprimido da UNINOVE, a Cátedra da Universidade Federal de Viçosa e a Cátedra Paulo Freire da Amazônia, vinculada à Universidade do Estado do Pará. No México, a Cátedra de Cuernavaca foi reinstalada em 2013.

No Brasil, as cátedras estão distribuídas em 04 regiões: Norte, Nordeste, Sudeste e Sul, predominando no estado de São Paulo. No México e na Argentina, as Cátedras estão distribuídas em estados diferenciados (Quadro 3). Em relação às demais Cátedras, poucas foram as informações obtidas em termos de vínculos institucionais e de ações educacionais.

Quadro 3

Cátedras Paulo Freire - Instituições e País

\begin{tabular}{|c|c|c|c|}
\hline Países & Cátedras & Instituições & Locais \\
\hline \multirow{8}{*}{ Brasil-08 } & Cátedra Paulo Freire & $\begin{array}{l}\text { Pontifícia Universidade Católica } \\
\text { de São Paulo - PUC-SP }\end{array}$ & São Paulo \\
\hline & Cátedra Paulo Freire & $\begin{array}{l}\text { Universidade Federal de } \\
\text { Pernambuco - UFPE }\end{array}$ & Recife \\
\hline & $\begin{array}{l}\text { Cátedra Paulo Freire de } \\
\text { Educação de Jovens e } \\
\text { Adultos }\end{array}$ & $\begin{array}{l}\text { Universidade Federal da } \\
\text { Integração Latino-Americana } \\
\text { - UNILA }\end{array}$ & Foz do lguaçu \\
\hline & Cátedra Livre Paulo Freire & $\begin{array}{l}\text { Universidade Federal de Viçosa } \\
\text { - UFV }\end{array}$ & Minas Gerais \\
\hline & Cátedra do Oprimido & $\begin{array}{l}\text { Universitas Paulo Freire- } \\
\text { UNIFREIRE. Instituto Paulo Freire/ } \\
\text { IPF e Universidade Nove de Julho/ } \\
\text { UNINOVE }\end{array}$ & São Paulo \\
\hline & Cátedra Paulo Freire & $\begin{array}{l}\text { Universidade Federal da Fronteira } \\
\text { Sul - UFFS }\end{array}$ & Erechim \\
\hline & Cátedra Paulo Freire & $\begin{array}{l}\text { Universidade Católica de Santos } \\
\text { - UNISANTOS }\end{array}$ & Santos \\
\hline & $\begin{array}{l}\text { Cátedra Paulo Freire da } \\
\text { Amazônia }\end{array}$ & $\begin{array}{l}\text { Universidade do Estado do Pará } \\
\text { - UEPA }\end{array}$ & Belém \\
\hline \multirow{3}{*}{ México-03 } & Cátedra Libre Paulo Freire & $\begin{array}{l}\text { Universidad Autonoma Chapingo } \\
-\cup A C H\end{array}$ & Chapingo \\
\hline & Cátedra Paulo Freire & $\begin{array}{l}\text { Universidad Jesuita de } \\
\text { Guadalajara - ITESO }\end{array}$ & Guadalajara \\
\hline & Cátedra Paulo Freire & $\begin{array}{l}\text { Universidad Autonoma del Estado } \\
\text { de Morelos - UAEM }\end{array}$ & Cuernavaca \\
\hline
\end{tabular}


Paulo Freire na América Latina e nos Estados Unidos: vátedras e grupos de pesquisas

\section{Quadro 3}

\section{Cátedras Paulo Freire - Instituições e País (Continuidade)}

\begin{tabular}{|c|c|c|c|}
\hline Países & Cátedras & Instituições & Locais (Cont.) \\
\hline \multirow{4}{*}{ Argentina- 04} & $\begin{array}{l}\text { Cátedra Libre de } \\
\text { Alfabetización "Paulo } \\
\text { Freire" }\end{array}$ & $\begin{array}{l}\text { Universidad Nacional } \\
\text { de San Luis - UNSL }\end{array}$ & San Luis \\
\hline & $\begin{array}{l}\text { Cátedra Libre Paulo } \\
\text { Freire }\end{array}$ & $\begin{array}{l}\text { Union de Trabajadores } \\
\text { de la educación - UTE }\end{array}$ & $\begin{array}{l}\text { Buenos Aires } \\
\text { Argentina }\end{array}$ \\
\hline & $\begin{array}{l}\text { Cátedra Abierta Paulo } \\
\text { Freire } \\
\end{array}$ & $\begin{array}{l}\text { Universidad Nacional } \\
\text { de Luján - UNLU }\end{array}$ & Luján \\
\hline & $\begin{array}{l}\text { Cátedra Abierta Paulo } \\
\text { Freire }\end{array}$ & $\begin{array}{l}\text { Universidad Nacional } \\
\text { de Entre Rios - UNER }\end{array}$ & Entre Rios \\
\hline \multirow[t]{2}{*}{ Costa Rica - 02} & Cátedra Paulo Freire & $\begin{array}{l}\text { Universidad Nacional } \\
\text { - UNA (Centro } \\
\text { de Investigación } \\
\text { e Docência em } \\
\text { Educación - CIDE) }\end{array}$ & $\begin{array}{l}\text { Heredia } \\
\text { Não encontrado } \\
\text { dados da Cátedra }\end{array}$ \\
\hline & Cátedra Paulo Freire & $\begin{array}{l}\text { Universidad de Costa } \\
\text { Rica- UCR }\end{array}$ & San José \\
\hline \multirow{4}{*}{ Colômbia 04} & Cátedra Paulo Freire & $\begin{array}{l}\text { Universidad } \\
\text { Pedagogica Nacional } \\
\text { - UPN }\end{array}$ & Bogotá \\
\hline & Cátedra Livre & $\begin{array}{l}\text { Universidad de Cauca } \\
\text { - UNICAUCA }\end{array}$ & Cauca-Popayán \\
\hline & $\begin{array}{l}\text { Cátedra Libre Paulo } \\
\text { Freire }\end{array}$ & $\begin{array}{l}\text { Universidad } \\
\text { Cundinamarca - UDEC }\end{array}$ & Cundinamarca \\
\hline & Cátedra Paulo Freire & $\begin{array}{l}\text { Universidad } \\
\text { DelAtlántico } \\
\text { - UNIATLÂNTICO }\end{array}$ & $\begin{array}{l}\text { Barranquilla } \\
\text { - Atlântico }\end{array}$ \\
\hline Cuba-Ol & $\begin{array}{l}\text { Cátedra de Estudios } \\
\text { Comunitarios Paulo } \\
\text { Freire }\end{array}$ & $\begin{array}{l}\text { Centro Provincial de } \\
\text { Superación para la } \\
\text { Cultura de Cienfuegos } \\
\text { - CPS }\end{array}$ & Cienfuegos \\
\hline Venezuela-01 & $\begin{array}{l}\text { Cátedra Paulo Freire y } \\
\text { la Americanidad }\end{array}$ & $\begin{array}{l}\text { Universidad Central de } \\
\text { Venezuela-UCV }\end{array}$ & Caracas \\
\hline Porto Rico - 01 & Cátedra Paulo Freire & $\begin{array}{l}\text { Universidade de Porto } \\
\text { Rico - UPR }\end{array}$ & Porto Rico \\
\hline
\end{tabular}

Fonte: Mafra e Gadotti (2005), site Instituto Paulo Freire (2014) e Sites (2014; 2015; $2017)$. 
A Argentina é que possui o maior número de Institutos, entretanto, o de maior diversidade e amplitude de ações é o Instituto Paulo Freire do Brasil. Nos demais Institutos, foram poucas as ações obtidas em termos de vínculos institucionais e ações educacionais (Quadro 4). Essa ausência de informações é verificada, sobretudo, pela ausência de sites ou quando existem, faltam informações ou não estão bem estruturados, o que dificulta a pesquisa. Algumas informações foram obtidas em sites com noticiários de universidades.

Quadro 4

Institutos Paulo Freire - Instituições e País

\begin{tabular}{|c|c|c|c|}
\hline Países & Institutos & Instituições & Locais \\
\hline Brasil - 01 & Instituto Paulo Freire & $\begin{array}{c}\text { Universitas Paulo Freire } \\
\text { - UNIFREIRE. Instituto } \\
\text { Paulo Freire/IPF }\end{array}$ & São Paulo \\
\hline \multirow{4}{*}{ Argentina- 04} & Instituto Paulo Freire & $\begin{array}{l}\text { Instituto de educación } \\
\text { superior de formación } \\
\text { docente y técnica Paulo } \\
\text { Freire - ISFD }\end{array}$ & Quilmes \\
\hline & $\begin{array}{c}\text { Instituto de investigacio- } \\
\text { nes Paulo Freire }\end{array}$ & $\begin{array}{l}\text { Universidad Nacional } \\
\text { de Rosario - UNR }\end{array}$ & Rosário \\
\hline & Instituto Paulo Freire & $\begin{array}{l}\text { Instituto de educación } \\
\text { superior de formación } \\
\text { docente y técnica Paulo } \\
\text { Freire - ISFD }\end{array}$ & Chacabuco \\
\hline & Instituto Paulo Freire & $\begin{array}{c}\text { Universidad Nacional } \\
\text { del Centro de La } \\
\text { Provincia de Buenos } \\
\text { Aires - UNICEN }\end{array}$ & $\begin{array}{c}\text { Tandil - Buenos Aires } \\
\text { Não encontrado dados } \\
\text { do Instituto }\end{array}$ \\
\hline Perú - 01 & $\begin{array}{l}\text { Instituto Superior } \\
\text { Pedagógico Paulo } \\
\text { Freire }\end{array}$ & $\begin{array}{l}\text { Asociación de } \\
\text { Desarrollo Educativo } \\
\text { Peruano Alemana } \\
\text { - ADEPA }\end{array}$ & Lima \\
\hline Venezuela - 01 & $\begin{array}{c}\text { Instituto Universitário } \\
\text { Agroecológico Latino- } \\
\text { Americano Paulo Freire } \\
\text { - IALA }\end{array}$ & $\begin{array}{l}\text { Governo Bolivariano da } \\
\text { Venezuela - GBV }\end{array}$ & Barinas \\
\hline \multicolumn{4}{|l|}{ TOTAL - O7 } \\
\hline
\end{tabular}

Fonte: Mafra e Gadotti (2005), site Instituto Paulo Freire (2014). 
Identificou-se a existência de uma Universidade Paulo Freire, em Manágua - Nicarágua, fundada em 18 de maio de 1998, que se constitui em uma Instituição de Educação Superior Humanista, com oferta do ensino das Ciências Jurídicas, Ciências Sociais e Econômicas, Ciências da Educação e de disciplinas como Direito do Trabalho, Direito da Família, Legislação, Gestão e política ambiental. Disponibiliza formação e educação aberta aplicáveis a todos os níveis técnico superior, licenciaturas, especialização e pós-graduação (Quadro 5).

\section{Quadro 5}

\section{Universidade Paulo Freire}

\begin{tabular}{|c|c|c|}
\hline País & Universidade & Local \\
\hline Nicarágua & Universidade Paulo Freire & Manágua \\
\hline
\end{tabular}

Site: http://www.ufp.edu.ni/2014).

Em relação aos 46 grupos de pesquisas no Brasil, a presença de Paulo Freire se concentra no Diretório do CNPq correspondendo a 39 (trinta e nove) grupos. Identificaram-se, ainda, mais 7 Grupos, constituídos por Centros e Núcleos de estudos freireanos (Quadro 6).

Os grupos de pesquisas do CNPq estão distribuídos nas regiões Sudeste (14), Sul (10), Nordeste (10) e Norte (05), perfazendo um total de 39. Não houve registro de grupo na região Centro-Oeste.

As escolas e colégios Paulo Freire aqui considerados são os que desenvolvem os princípios educacionais de Paulo Freire, não tendo apenas o nome do educador. Isto porque foi encontrado um número significativo de escolas com o nome Paulo Freire (Quadro 6). 


\section{Quadro 6}

Grupos por Região, Estado e Universidades

\begin{tabular}{|c|c|c|c|}
\hline Países & $\begin{array}{c}\text { Centros/Escolas/Redes/ Grupos/ } \\
\text { Núcleos de Pesquisas }\end{array}$ & Instituições & Locais \\
\hline \multirow{6}{*}{ Brasil 46} & $\begin{array}{c}39 \text { Grupos de Pesquisas vincu- } \\
\text { lados ao Conselho Nacional } \\
\text { de Desenvolvimento Cientifico e } \\
\text { Tecnológico - CNPq- }\end{array}$ & Ver quadro 8 & Ver quadro 8 \\
\hline & $\begin{array}{c}\text { Rede Freireana de Pesquisadores } \\
- \text { RFP }\end{array}$ & $\begin{array}{l}\text { Pontificia Universidade } \\
\text { Católica de São Paulo } \\
\text { - PUC-SP }\end{array}$ & São Paulo \\
\hline & $\begin{array}{c}\text { Grupo de Pesquisa Educação } \\
\text { Popular na Universidade - GRUPEJU }\end{array}$ & $\begin{array}{c}\text { Universidade Federal } \\
\text { da Fronteira do Sul } \\
\text { - UFFS }\end{array}$ & Erechim \\
\hline & $\begin{array}{c}\text { Grupo de Estudos Paulo Freire } \\
\text { - FACCAT }\end{array}$ & $\begin{array}{c}\text { Faculdade de } \\
\text { Educação das } \\
\text { Faculdades Integradas } \\
\text { de Taquara - FACCAT }\end{array}$ & Taquara \\
\hline & Curso Paulo Freire - CPF & $\begin{array}{c}\text { Faculdade de Direito } \\
\text { da Universidade } \\
\text { Federal do Ceará } \\
\text { - UFC }\end{array}$ & Fortaleza \\
\hline & $\begin{array}{c}\text { Centro Paulo Freire: estudos e } \\
\text { pesquisas - CPF }\end{array}$ & - & Recife \\
\hline Colômbia 01 & $\begin{array}{c}\text { Centro Educativo Paulo Freire } \\
\text { - CEPF }\end{array}$ & $\begin{array}{c}\text { Universidad } \\
\text { Bucaramanga - UB }\end{array}$ & Bogotá \\
\hline Peru 01 & El Foro - Red Paulo Freire - Perú & $\begin{array}{c}\text { Educadores/as } \\
\text { populares }\end{array}$ & Lima \\
\hline \multirow{3}{*}{ Chile 03} & Escuela Popular Paulo Freire & $\begin{array}{l}\text { Pontificia Universidad } \\
\text { Católica de Chile } \\
\text { - PUC-Chile }\end{array}$ & $\begin{array}{c}\text { Campi San } \\
\text { Joaquim - Santiago }\end{array}$ \\
\hline & Colégio Paulo Freire & $\begin{array}{l}\text { Movimiento de } \\
\text { Pobladores en lucha }\end{array}$ & Santiago \\
\hline & Colectivo Paulo Freire & $\begin{array}{l}\text { Educadores/as } \\
\text { populares }\end{array}$ & Santiago \\
\hline Argentina 01 & $\begin{array}{c}\text { Núcleo de Estudios Educacionales y } \\
\text { Sociales - NEES }\end{array}$ & $\begin{array}{l}\text { Universidad Nacional } \\
\text { del Centro de La } \\
\text { Provincia de Buenos } \\
\text { Aires-UNCPBA }\end{array}$ & Tandil \\
\hline
\end{tabular}

Fontes: sites (2014; 2015). 
Em termos dos Grupos de Estudos sobre o Paulo Freire, encontraram-se vários termos e aspectos: Grupos, Núcleos, Redes, Curso, Centro, Escola, Coletivo e Fórum (Quadro 7).

\section{Quadro 7}

$N^{\circ}$ Centros, Redes Escolas e Grupos de Pesquisas por países

\begin{tabular}{|c|c|c|}
\hline Países & $\mathrm{N}^{\circ}$ & Centros, Redes, etc. \\
\hline \multirow{4}{*}{ Brasil } & 39 & $\begin{array}{c}\text { Grupos de Pesquisa diretório } \\
\text { do CNPq }\end{array}$ \\
\cline { 2 - 3 } & 02 & Grupos de pesquisas \\
\cline { 2 - 3 } & 01 & Rede de pesquisa \\
\cline { 2 - 3 } & 01 & Núcleos \\
\cline { 2 - 3 } & 01 & Cursos \\
\cline { 2 - 3 } & 02 & Centros \\
\hline Colômbia & 01 & Centro \\
\hline Argentina & 01 & Núcleo \\
\hline Perú & 01 & Fórum/Rede \\
\hline \multirow{2}{*}{ Chile } & 02 & Escuelas \\
\cline { 2 - 3 } & 01 & Colectivo \\
\hline Total & \multicolumn{2}{|c|}{52} \\
\hline
\end{tabular}

Fontes: sites (2014 e 2015).

levantamento de 2011 para 2015 dos grupos de pesquisa do CNPq evidenciou um crescimento de grupos de pesquisas sobre o Paulo Freire de 28 para 39 (Quadro 8). Esse crescimento foi evidenciado nas regiões Norte e Nordeste com um novo grupo cada; no Sul com três, e no Sudeste com seis novos grupos (Quadro 9). 


\section{Quadro 8}

\section{Grupos de Pesquisas e Instituições}

\begin{tabular}{|c|c|c|}
\hline $\mathrm{N}^{\circ}$. & Grupos de Pesquisas & Instituições \\
\hline 01 & A Educação Popular e os Estudos Indiciários & Universidade Federal da Paraíba - UFPB \\
\hline 02 & Núcleo de Educação Popular Paulo Freire & Universidade do Estado do Pará - UEPA \\
\hline 03 & $\begin{array}{l}\text { Educação Popular na Geografia: Ação e } \\
\text { Pesquisa }\end{array}$ & Universidade Federal de Pelotas - UFPEL \\
\hline 04 & $\begin{array}{l}\text { Estudos pedagógicos: formação docente e gestão } \\
\text { educacional }\end{array}$ & $\begin{array}{l}\text { Universidade Regional Integrada do Alto } \\
\text { Uruguai e das Missões - URI }\end{array}$ \\
\hline 05 & Filosofia, Educação e Práxis Social & Universidade Federal de Pelotas - UFPEL \\
\hline 06 & $\begin{array}{l}\text { Grupo de Estudos e Pesquisas em Educação } \\
\text { Ambiental Dialógica, Educação Intercultural, } \\
\text { Descolonialidade, Educação e Cultura Popular }\end{array}$ & Universidade Federal do Ceará - UFC \\
\hline 07 & Formação de Professores e Ensino de Ciências & Universidade Federal de Alagoas - UFAL \\
\hline 08 & Grupo de Estudos e Pesquisa Paulo Freire & $\begin{array}{l}\text { Universidade Estadual de Santa Cruz } \\
\text { - UESC }\end{array}$ \\
\hline 09 & $\begin{array}{l}\text { Núcleo de Estudo Pesquisa e Extensão } \\
\text { Educacional Paulo Freire }\end{array}$ & Universidade do Estado da Bahia - UNEB \\
\hline 10 & $\begin{array}{l}\text { Lugar da Interdisciplinaridade no Discurso de } \\
\text { Paulo Freire }\end{array}$ & Universidade de Pernambuco - UPE \\
\hline 11 & Práticas Educativas Emancipatórias & $\begin{array}{l}\text { Pontifícia Universidade Católica do Rio } \\
\text { Grande do Sul - PUCRS }\end{array}$ \\
\hline 12 & Práxis & Universidade Federal de Rondônia - UNIR \\
\hline 13 & Grupo de Estudos e Pesquisa Paulo Freire & $\begin{array}{l}\text { Universidade Metodista de São Paulo } \\
\text { - UMESP }\end{array}$ \\
\hline 14 & $\begin{array}{l}\text { O discurso pedagógico de Paulo Freire: uma } \\
\text { leitura }\end{array}$ & Universidade Presbiteriana Mackenzie \\
\hline 15 & Paulo Freire: gnoseologia, realidade e educação & $\begin{array}{l}\text { Universidade Federal Rural do Semiárido } \\
\text { - UFERSA }\end{array}$ \\
\hline 16 & $\begin{array}{l}\text { Pensando Bem - Núcleo de Pesquisa em Filosofia } \\
\text { e Educação }\end{array}$ & Universidade Federal de Juiz de Fora - UFJF \\
\hline 17 & $\begin{array}{l}\text { Grupo de Estudo e Pesquisa em Educação do } \\
\text { Campo na Amazônia }\end{array}$ & Universidade Federal do Pará - UFPA \\
\hline 18 & MovSE: Movimentos Sociais e Educação Popular & Universidade Federal de Pelotas - UFPEL \\
\hline 19 & Filosofia e Educação -Educogitans & $\begin{array}{l}\text { Fundação Universidade Regional de } \\
\text { Blumenau - FURB }\end{array}$ \\
\hline 20 & $\begin{array}{l}\text { Grupo de Estudos de Práticas Educativas em } \\
\text { Movimento }\end{array}$ & $\begin{array}{l}\text { Universidade Federal do Rio Grande do } \\
\text { Norte - UFRN }\end{array}$ \\
\hline
\end{tabular}


Paulo Freire na América Latina e nos Estados Unidos: vátedras e grupos de pesquisas

\section{Quadro 8}

\section{Grupos de Pesquisas e Instituições (Continuidade)}

\begin{tabular}{|c|c|c|}
\hline $\mathrm{N}^{\circ}$. & Grupos de Pesquisas & Instituições \\
\hline 21 & GT - Pedagogia e Teatro do Oprimido & Universidade Federal de Ouro Preto - UFOP \\
\hline 22 & $\begin{array}{l}\text { O pensamento de Paulo Freire na educação } \\
\text { brasileira }\end{array}$ & $\begin{array}{l}\text { Pontifícia Universidade Católica de são Paulo } \\
\text { - PUC-SP }\end{array}$ \\
\hline 23 & $\begin{array}{l}\text { Movimentos Sociais, Educação popular e } \\
\text { escola }\end{array}$ & Universidade Federal do Ceará - UFC \\
\hline 24 & Educação, culturas e ações coletivas e Estado & $\begin{array}{l}\text { Universidade Federal do Rio Grande do Sul } \\
\text { - UFRGS }\end{array}$ \\
\hline 25 & Práticas Sociais e Processos Educativos & Universidade Federal de São Carlos - UFSCAR \\
\hline 26 & Epidemiologia clínica e educação em saúde & Universidade de São Paulo - USP \\
\hline 27 & Núcleo de Educação de Jovens e Adultos & $\begin{array}{l}\text { Universidade Federal de Minas Gerais } \\
\text { - UFMG }\end{array}$ \\
\hline 28 & $\begin{array}{l}\text { Grupo Sala Verde Pororoca: espaço socioam- } \\
\text { biental Paulo Freire }\end{array}$ & Universidade Federal do Pará - UFPA \\
\hline 29 & Grupo de Pesquisas Freirianas em Educação & Universidade Nove de Julho - UNINOVE \\
\hline 30 & Educação em Ciências em Diálogo & Universidade Federal de Santa Maria - UFSM \\
\hline 31 & $\begin{array}{l}\text { Grupo de Pesquisa-Educação em rede: cultu- } \\
\text { ra, ciência, tecnologia e formação }\end{array}$ & Universidade Nove de Julho - UNINOVE \\
\hline 32 & $\begin{array}{l}\text { GEPÊPrivação - Grupo de Estudos e Pesquisas } \\
\text { sobre Educação em Regimes de Privação da } \\
\text { Liberdade }\end{array}$ & Universidade de São Paulo - USP \\
\hline 33 & CEl: Currículo e Educação Integral & $\begin{array}{l}\text { Pontifícia Universidade Católica de Minas - } \\
\text { PUC Minas }\end{array}$ \\
\hline 34 & $\begin{array}{l}\text { Grupo de Estudos e Pesquisa em Educação: } \\
\text { teoria e prática }\end{array}$ & Universidade Estadual do Paraná - UNESPAR \\
\hline 35 & $\begin{array}{l}\text { José Veríssimo e o Pensamento Educacional } \\
\text { Latino-americano }\end{array}$ & Universidade Federal do Pará - UFPA \\
\hline 36 & $\begin{array}{l}\text { DIALOGUS - Educação, Formação e } \\
\text { Humanização com Paulo Freire }\end{array}$ & Universidade Federal de Santa Maria - UFSM \\
\hline 37 & $\begin{array}{l}\text { ECOS - Escola Contemporânea e Olhar } \\
\text { Sociológico }\end{array}$ & $\begin{array}{l}\text { Universidade Federal do Rio Grande do Norte } \\
\text { - UFRN }\end{array}$ \\
\hline 38 & $\begin{array}{l}\text { GEPGEP - Grupo de Estudo e Pesquisa } \\
\text { Geografia e Educação Popular }\end{array}$ & Universidade Federal de Uberlândia - UFU \\
\hline 39 & $\begin{array}{l}\text { Núcleo de estudo e pesquisa sobre saúde, } \\
\text { políticas públicas e sociais }\end{array}$ & Universidade Federal de São Paulo - UNIFESP \\
\hline
\end{tabular}

Fonte: Diretório CNPq (2011; 2014; 2015). 
Um olhar para os grupos de pesquisas, contidos no quadro 8, aponta para estudos e pesquisas sobre a educação de Paulo Freire, em geral, outras para particularidades do seu pensamento educacional, como a educação popular, a educação de jovens e adultos, cultura popular, fundamentos teóricos de sua pedagogia, entre outras, e relacionado a outros campos de conhecimento, entre os quais: a saúde, a geografia, o ensino de ciências, a educação ambiental e o teatro. Estudos que apontam a abrangência do pensamento educacional de Paulo Freire extrapolam o território da educação.

É provável que essa diversificação de estudos sobre Paulo Freire se deva a três aspectos, em relação à sua educação: (1) a fundamentação ética e humanista, situando o ser humano no centro do contexto educacional; (2) a dimensão política, destacada pelo comprometimento com as classes populares e o olhar para as relações de poder existentes no cotidiano educacional e, por fim, (3) a preocupação com a reflexão crítica sobre a prática educacional, visando transformá-la. A práxis viabiliza processos de mudanças no cenário educacional e dimensiona as ações dos sujeitos como históricas e emancipadoras, capazes de superar os discursos fatalistas e imobilizantes.

Para Paulo Freire é impossível pensar:

Na superação da opressão, da discriminação, da passividade ou da pura rebelião que elas engendram, primeiro, sem uma compreensão crítica da História, na qual, finalmente, essas relações interculturais se dão de forma dialética, por isso contraditória e processual. Segundo, sem projetos de natureza político-pedagógica no sentido da transformação ou da re-invenção do mundo [...] o que temos a fazer é repor o ser humano que atua, que pensa, que fala, que sonha, que ama, que odeia, que cria e recria, que sabe e ignora, que se afirma e que se nega, que constrói e destrói, que é tanto o que herda quanto o que adquire, no centro de nossas preocupações (FREIRE, 1993, p. 32 e 14, grifos do autor.).

Os grupos de pesquisas estão vinculados a 30 instituições de ensino superior, sendo predominantes as universidades públicas. As instituições com mais grupos de pesquisas foram: Universidade Federal do Pará - UFPA (03), Universidade Federal de Pelotas - UFPel (03), Universidade Federal do Rio Grande do Norte - UFRN (02), Universidade Federal de Santa Maria - UFSM (02) e Universidade Nove de Julho - UNINOVE (02). 
Paulo Freire na América Latina e nos Estados Unidos: vátedras e grupos de pesquisas

\section{Quadro 9}

Grupos de Pesquisa do CNPq por Região, Estado e Universidade

\begin{tabular}{|c|c|c|c|c|}
\hline Região & Estados & Universidades & $\begin{array}{c}\text { Total por } \\
\text { Universidade }\end{array}$ & $\begin{array}{l}\text { Total de } \\
\text { Grupos }\end{array}$ \\
\hline \multirow{3}{*}{ Norte } & \multirow{2}{*}{ Pará } & $\begin{array}{c}\text { Universidade do Estado do Pará } \\
\text { - UEPA }\end{array}$ & 01 & \multirow{3}{*}{05} \\
\hline & & $\begin{array}{c}\text { Universidade Federal do Pará } \\
\text { - UFPA }\end{array}$ & 03 & \\
\hline & Rondônia & $\begin{array}{c}\text { Universidade Federal de Rondônia } \\
\text { - UNIR }\end{array}$ & 01 & \\
\hline \multirow{7}{*}{ Nordeste } & Ceará & $\begin{array}{c}\text { Universidade Federal do Ceará } \\
\text { - UFC }\end{array}$ & 02 & \multirow{7}{*}{10} \\
\hline & \multirow{2}{*}{ Rio Grande do Norte } & $\begin{array}{c}\text { Universidade Federal do Rio } \\
\text { Grande do Norte - UFRN }\end{array}$ & 02 & \\
\hline & & $\begin{array}{l}\text { Universidade Federal Rural do } \\
\text { Semi-Árido - UFERSA }\end{array}$ & 01 & \\
\hline & Paraíba & $\begin{array}{c}\text { Universidade Federal da Paraíba } \\
\text { - UFPB }\end{array}$ & 01 & \\
\hline & Alagoas & $\begin{array}{c}\text { Universidade Federal de Alagoas } \\
\text { - UFAL }\end{array}$ & 01 & \\
\hline & Bahia & $\begin{array}{c}\text { Universidade do Estado da Bahia } \\
\text { - UNEB }\end{array}$ & 01 & \\
\hline & Pernambuco & Universidade de Pernambuco - UPE & 01 & \\
\hline \multirow{7}{*}{ Sul } & \multirow{5}{*}{ Rio Grande do Sul } & $\begin{array}{c}\text { Universidade Federal de Pelotas } \\
\text { - UFPEL }\end{array}$ & 03 & \multirow{7}{*}{10} \\
\hline & & $\begin{array}{c}\text { Universidade Regional Integrada } \\
\text { do Alto Uruguai - URI }\end{array}$ & 01 & \\
\hline & & $\begin{array}{c}\text { Universidade Federal do Rio } \\
\text { Grande do Sul - UFRGS }\end{array}$ & 01 & \\
\hline & & $\begin{array}{l}\text { Pontifícia Universidade Católica } \\
\text { do Rio Grande do Sul - PUCRS }\end{array}$ & 01 & \\
\hline & & $\begin{array}{c}\text { Universidade Federal de Santa } \\
\text { Maria - UFSM }\end{array}$ & 02 & \\
\hline & Santa Catarina & $\begin{array}{l}\text { Universidade Federal de Blu- } \\
\text { menau - FURB }\end{array}$ & 01 & \\
\hline & Paraná & $\begin{array}{c}\text { Universidade Estadual do Paraná } \\
\text { - UNESPAR }\end{array}$ & 01 & \\
\hline
\end{tabular}




\section{Quadro 9}

Grupos de Pesquisa do CNPq por Região, Estado e Universidade (Continuidade)

\begin{tabular}{|c|c|c|c|c|}
\hline Região & Estados & Universidades & $\begin{array}{c}\text { Total por } \\
\text { Universidade }\end{array}$ & $\begin{array}{l}\text { Total de } \\
\text { Grupos }\end{array}$ \\
\hline \multirow{12}{*}{ Sudeste } & \multirow{7}{*}{ São Paulo } & Universidade de São Paulo - USP & 02 & \multirow{12}{*}{14} \\
\hline & & $\begin{array}{c}\text { Universidade nove de Julho } \\
\text { - UNINOVE }\end{array}$ & 02 & \\
\hline & & $\begin{array}{l}\text { Universidade Presbiteriana } \\
\text { Mackenzie }\end{array}$ & 01 & \\
\hline & & $\begin{array}{l}\text { Universidade Metodista de São } \\
\text { Paulo - UMESP }\end{array}$ & 01 & \\
\hline & & $\begin{array}{l}\text { Universidade Federal de São } \\
\text { Carlos - UFSCAR }\end{array}$ & 01 & \\
\hline & & $\begin{array}{c}\text { Pontifícia Universidade Cató-lica de } \\
\text { São Paulo - PUC/SP }\end{array}$ & 01 & \\
\hline & & $\begin{array}{c}\text { Universidade Federal de São Paulo } \\
\text { - UNIFESP }\end{array}$ & 01 & \\
\hline & \multirow{5}{*}{$\begin{array}{l}\text { Minas } \\
\text { Gerais }\end{array}$} & $\begin{array}{l}\text { Universidade Federal de Mi-nas } \\
\text { Gerais - UFMG }\end{array}$ & 01 & \\
\hline & & $\begin{array}{l}\text { Universidade Federal de Juiz de } \\
\text { Fora - UFJF }\end{array}$ & 01 & \\
\hline & & $\begin{array}{c}\text { Universidade Federal de Ouro Preto } \\
\text { - UFOP }\end{array}$ & 01 & \\
\hline & & $\begin{array}{c}\text { Pontifícia Universidade Cató-lica de } \\
\text { Minas Gerais - PUC/MG }\end{array}$ & 01 & \\
\hline & & $\begin{array}{l}\text { Universidade Federal de Uber- } \\
\text { lândia - UFU }\end{array}$ & 01 & \\
\hline \multicolumn{4}{|l|}{ Total } & 39 \\
\hline
\end{tabular}

Fonte: Diretório CNPq (2011; 2014; 2015).

É evidente que não há diferenças entre as Cátedras e os Institutos pois ambos realizam as mesmas atividades pesquisa, ensino, eventos e publicações. Dessa forma, mudam-se as nomenclaturas, mas as ações são as mesmas.

Dos 45 Institutos/Grupos/Cátedras/Universidades analisados', sem incluir os Grupos do CNPq, 31 desenvolvem o ensino, com cursos de formação, 24 pesquisas, 37 eventos ou atividades culturais e 12 publicam. Somente 02, o Instituto de Tandil e a Cátedra de Paulo Freire de Porto Rico não foram encontradas informações sobre as ações desenvolvidas. 
Paulo Freire na América Latina e nos Estados Unidos: vátedras e grupos de pesquisas

Dos 43 Institutos/Grupos/Cátedras/Universidades onde foram encontradas as informações, 10 realizam pesquisa, ensino, eventos e publicam; 08 desenvolvem pesquisa, ensino e eventos, 06 promovem eventos e ensino, 07 somente eventos, 05 somente o ensino, 04 pesquisa e eventos, 01 pesquisa e ensino, 01 pesquisa, evento e publicação, 01 ensino, evento e publicação (Quadro 10).

\section{Quadro 10}

Ações das Cátedras, Institutos/Universidade Paulo Freire

\begin{tabular}{|c|c|c|c|c|c|}
\hline Cátedra/Inst/Grupos/Univ. & Local/País & \multicolumn{4}{|c|}{ Atividades } \\
\hline Instituto Paulo Frei-re & Quilmes - Argentina & - & Ensino & - & - \\
\hline $\begin{array}{l}\text { Instituto de inves-tigaciones } \\
\text { Paulo Freire }\end{array}$ & Rosário - Argentina & Pesquisa & Ensi-no & Ev/cult. & - \\
\hline Instituto Paulo Freire & $\begin{array}{l}\text { Chacabuco } \\
\text { - Argentina }\end{array}$ & - & & - & - \\
\hline Instituto Paulo Freire & Tandil - Argentina & NE & NE & $\mathrm{NE}$ & NE \\
\hline Instituto Paulo Freire & São Paulo - Brasil & Pesquisa & Ensi-no & Ev/cult. & Pub. \\
\hline $\begin{array}{c}\text { Instituto Superior Pedagógico } \\
\text { Pau-lo Freire }\end{array}$ & Lima - Perú & - & Ensi-no & Ev/cult. & - \\
\hline $\begin{array}{l}\text { Instituto Universitá- } \\
\text { rio Agroecológico } \\
\text { Latino-Americano Paulo Freire } \\
- \text { IALA }\end{array}$ & Barinas - Venezuela & - & Ensi-no & Ev/cult. & - \\
\hline Cátedra Paulo Freire & Pernambuco - Brasil & Pesquisa & Ensi-no & Ev/cult. & Pub. \\
\hline Cátedra Paulo Freire & São Paulo - Brasil & Pesquisa & Ensino & Ev/cult. & Pub. \\
\hline Cátedra do Opri-mido & São Paulo - Brasil & Pesquisa & Ensino & Ev/cult. & Pub. \\
\hline $\begin{array}{c}\text { Cátedra Paulo Frei-re de } \\
\text { Educação de Jovens e Adultos }\end{array}$ & Foz do Iguaçu - Brasil & - & Ensino & Ev/cult. & - \\
\hline Cátedra Paulo Frei-re & Santos - Brasil & - & Ensino & Ev/cult. & - \\
\hline Cátedra Livre Paulo Freire & Minas Gerais - Brasil & - & Ensino & Ev/cult. & Pub. \\
\hline Cátedra Paulo Freire & Frechim - Brasil & Pesquisa & Ensino & Ev/cult. & Pub. \\
\hline $\begin{array}{l}\text { Cátedra Paulo Freire da } \\
\text { Amazônia }\end{array}$ & Belém - Brasil & Pesquisa & Ensino & Ev/cult. & Pub. \\
\hline $\begin{array}{c}\text { Cátedra de Estudios } \\
\text { Comunitarios Paulo Freire }\end{array}$ & Cienfuegos - Cuba & - & - & Ev/cult. & - \\
\hline
\end{tabular}




\section{Quadro 10}

\section{Ações das Cátedras, Institutos/ Universidade Paulo Freire (Continuidade)}

\begin{tabular}{|c|c|c|c|c|c|}
\hline Cátedra/Inst/Grupos/Univ. & Local/País & \multicolumn{4}{|c|}{ Atividades } \\
\hline $\begin{array}{c}\text { Cátedra Paulo Freire y la } \\
\text { Americanidad }\end{array}$ & Caracas - Venezuela & - & - & $\begin{array}{l}\text { Ev/ } \\
\text { cult. }\end{array}$ & - \\
\hline Cátedra Libre Paulo Freire & Chapingo - México & Pesquisa & Ensino & $\begin{array}{l}\text { Ev/ } \\
\text { cult. }\end{array}$ & - \\
\hline Cátedra Paulo Freire & Guadalajara-México & Pesquisa & Ensino & $\begin{array}{l}\text { Ev/ } \\
\text { cult. }\end{array}$ & Pub. \\
\hline Cátedra Paulo Freire & Cuernavaca - México & Pesquisa & Ensino & - & - \\
\hline $\begin{array}{c}\text { Cátedra Libre de Alfabetización } \\
\text { "Paulo Freire" }\end{array}$ & San Luis - Argentina & Pesquisa & Ensino & $\begin{array}{l}\text { Ev/ } \\
\text { cult. }\end{array}$ & - \\
\hline Cátedra Libre Paulo Freire & Buenos Aires - Argen-tina & Pesquisa & Ensino & $\begin{array}{l}\text { Ev/ } \\
\text { cult. }\end{array}$ & - \\
\hline Cátedra Abierta Paulo Freire & Luján - Argentina & - & - & $\begin{array}{l}\text { Ev/ } \\
\text { cult. }\end{array}$ & - \\
\hline Cátedra Abierta Paulo Freire & Entre Rios - Argentina & Pesquisa & - & $\begin{array}{l}\text { Ev/ } \\
\text { cult. }\end{array}$ & Pub. \\
\hline Cátedra Paulo Freire & Heredia - Costa Rica & - & - & $\begin{array}{l}\text { Ev/ } \\
\text { cult. }\end{array}$ & - \\
\hline Cátedra Paulo Freire & San José - Costa Rica & - & - & $\begin{array}{l}\text { Ev/ } \\
\text { cult. }\end{array}$ & - \\
\hline Cátedra Paulo Freire & Bogotá - Colômbia & Pesquisa & Ensino & $\begin{array}{l}\text { Ev/ } \\
\text { cult. }\end{array}$ & Pub. \\
\hline Cátedra Livre & Cauca - Colômbia & Pesquisa & Ensino & $\begin{array}{l}\text { Ev/ } \\
\text { cult. }\end{array}$ & - \\
\hline Cátedra Libre Paulo Freire & $\begin{array}{l}\text { Cundinamarca } \\
\text { - Colômbia }\end{array}$ & - & - & $\begin{array}{l}\text { Ev/ } \\
\text { cult. }\end{array}$ & - \\
\hline Cátedra Paulo Frei-re & Atlântico - Colômbia & Pesquisa & Ensino & $\begin{array}{l}\text { Ev/ } \\
\text { cult. }\end{array}$ & - \\
\hline Cátedra Paulo Freire & Porto Rico & NE & NE & NE & NE \\
\hline $\begin{array}{c}\text { Rede Freireana de Educação } \\
\text { - RFE }\end{array}$ & São Paulo - Brasil & Pesquisa & - & $\begin{array}{l}\text { Ev/ } \\
\text { cult. }\end{array}$ & - \\
\hline $\begin{array}{c}\text { Grupo de Pesquisa Educação } \\
\text { Popular na Universidade } \\
\text { - GRUPEJU }\end{array}$ & Erechim - Brasil & Pesquisa & - & $\begin{array}{l}\text { Ev/ } \\
\text { cult. }\end{array}$ & - \\
\hline $\begin{array}{c}\text { Grupo de Estudos Paulo Freire } \\
\text { - FAC-CAT }\end{array}$ & Taquara - Brasil & Pesquisa & Ensino & $\begin{array}{l}\text { Ev/ } \\
\text { cult. }\end{array}$ & Pub. \\
\hline
\end{tabular}


Paulo Freire na América Latina e nos Estados Unidos: vátedras e grupos de pesquisas

\section{Quadro 10}

Ações das Cátedras, Institutos/Universidade Paulo Freire (Continuidade)

\begin{tabular}{|c|c|c|c|c|c|}
\hline Cátedra/Inst/Grupos/Univ. & Local/País & \multicolumn{3}{|c|}{ Atividades } \\
\hline Núcleo Paulo Freire -NPF & Recife - Brasil & Pesquisa & Ensino & Ev/cult. & - \\
\hline $\begin{array}{c}\text { Centro de Refe-rência Paulo Freire: } \\
\text { memória e presença - CRPF }\end{array}$ & São Paulo - Brasil & Pesquisa & - & Ev/cult. & - \\
\hline Curso Paulo Freire - CPF & Fortaleza - Brasil & - & Ensino & - & - \\
\hline $\begin{array}{c}\text { Centro Paulo Freire: estudos e pesqui- } \\
\text { sas - CPF }\end{array}$ & Recife - Brasil & Pesquisa & - & Ev/cult. & - \\
\hline $\begin{array}{c}\text { Centro Educativo Paulo Freire - CEPF } \\
\text { El Foro - Red Paulo Freire - Perú }\end{array}$ & Bogotá - Colômbia & - & Ensino & - & - \\
\hline Escuela Popular Paulo Freire & Santiago - Chile & - & Ensino & Ev/cult. & - \\
\hline Colégio Paulo Freire & Santiago - Chile & - & Ensino & Ev/cult. & - \\
\hline Colectivo Paulo Freire & Santiago - Chile & Pesquisa & Ensino & Ev/cult. & Pub. \\
\hline $\begin{array}{c}\text { Núcleo de Estudios Educacionalesy } \\
\text { Sociales - NEES }\end{array}$ & Tandil - Argentina & - & Ensino & - & - \\
\hline Universidade Paulo Freire & Manágua - Nicarágua & Pesquisa & Ensino & Ev/cult. & - \\
\hline
\end{tabular}

Fonte: sites dos Institutos/Grupos/Cátedras (2014; 2015).

Dos 39 grupos de pesquisas vinculados ao CNPq, identificou-se que 39 pesquisam, 12 realizam ensino, 11 eventos e 16 publicações. 07 desenvolvem pesquisa, ensino, eventos e publicações, 07 pesquisam e publicam, 04 pesquisam e ensinam, 01 realiza pesquisa, ensino e eventos, 02 pesquisam e realizam eventos e 02 pesquisam, realizam eventos e publicam (Quadro 11 ).

Entre as IES que realizam articuladamente pesquisa, ensino, extensão, eventos culturais e publicação estão: Universidade Estadual de Santa Cruz UESC (Ilhéus/Bahia); Pontifícia Universidade Católica de São Paulo - PUC/SP (São Paulo/SP), Universidade Federal de Santa Maria - UFSM (Santa Maria/ RS), Universidade do Estado do Pará - UEPA (Belém/PA), Universidade Estadual da Bahia (UNEB) e Universidade Estadual do Paraná - UNESPAR (Paranavaí/ PR) e Universidade Federal de Minas Gerais - UFMG. A maioria informa, no descritor do grupo, que realiza, apenas, pesquisa. 


\section{Quadro 11}

\section{Ações dos Grupos de Pesquisa s/Paulo Freire - Diretório do CNPq}

\begin{tabular}{|c|c|c|c|c|c|}
\hline Instituições & Local/País & \multicolumn{4}{|c|}{ Atividades } \\
\hline $\begin{array}{l}\text { Universidade Estadual de Santa } \\
\text { Cruz - UESC }\end{array}$ & Ithéus/Bahia & Pesquisa & Ensino & $\begin{array}{l}\text { Ev/ } \\
\text { Cult. }\end{array}$ & Pub. \\
\hline $\begin{array}{c}\text { Pontifícia Universidade Católica } \\
\text { de São Paulo - PUC-SP }\end{array}$ & São Paulo/SP & Pesquisa & Ensino & $\begin{array}{l}\text { Ev/ } \\
\text { Cult. }\end{array}$ & Pub. \\
\hline $\begin{array}{c}\text { Universidade Federal de Santa } \\
\text { Maria - UFSM }\end{array}$ & Santa Maria/RS & Pesquisa & Ensino & $\begin{array}{l}\text { Ev/ } \\
\text { Cult. }\end{array}$ & Pub. \\
\hline $\begin{array}{c}\text { Universidade do Estado do Pará } \\
\text { - UEPA }\end{array}$ & Belém/PA & Pesquisa & Ensino & $\begin{array}{l}\text { Ev/ } \\
\text { Cult. }\end{array}$ & Pub. \\
\hline $\begin{array}{l}\text { Pontifícia Universidade Católica } \\
\text { do Rio Grande do Sul - PUC/RS }\end{array}$ & Porto Alegre/RS & Pesquisa & - & $\begin{array}{l}\text { Ev/ } \\
\text { Cult. }\end{array}$ & Pub. \\
\hline $\begin{array}{l}\text { Universidade Metodista de São } \\
\text { Paulo - UMESP }\end{array}$ & São Paulo/SP & Pesquisa & - & - & Pub. \\
\hline $\begin{array}{l}\text { Universidade Federal Rural do } \\
\text { Semi-Árido - UFERSA }\end{array}$ & Angicos/RN & Pesquisa & - & - & - \\
\hline $\begin{array}{c}\text { Universidade Federal de } \\
\text { Rondônia - UNIR }\end{array}$ & Porto Velho/RO & Pesquisa & - & - & Pub. \\
\hline $\begin{array}{l}\text { Universidade Federal de } \\
\text { Uberlândia - UFU }\end{array}$ & Uberlândia/MG & Pesquisa & - & - & Pub. \\
\hline $\begin{array}{c}\text { Universidade Federal do Pará } \\
\text { - UFPA }\end{array}$ & Belém/PA & Pesquisa & - & - & - \\
\hline $\begin{array}{c}\text { Universidade Federal do Pará } \\
\text { - UFPA }\end{array}$ & Belém/PA & Pesquisa & Ensino & - & - \\
\hline $\begin{array}{c}\text { Universidade Federal do Pará } \\
\text { - UFPA }\end{array}$ & Belém/PA & Pesquisa & & $\begin{array}{l}\text { Ev/ } \\
\text { Cult. }\end{array}$ & Pub. \\
\hline $\begin{array}{l}\text { Universidade Estadual do } \\
\text { Paraná - UNESPAR }\end{array}$ & Paraná & Pesquisa & Ensino & $\begin{array}{l}\text { Ev/ } \\
\text { Cult. }\end{array}$ & Pub. \\
\hline $\begin{array}{l}\text { Universidade do Estado da } \\
\text { Bahia - UNEB }\end{array}$ & Salvador/Bahia & Pesquisa & Ensino & $\begin{array}{l}\text { Ev/ } \\
\text { Cult. }\end{array}$ & Pub. \\
\hline $\begin{array}{c}\text { Universidade de Per-nambuco } \\
\text { - UPE }\end{array}$ & Pernambuco & Pesquisa & - & - & - \\
\hline $\begin{array}{l}\text { Pontifícia Universidade Católica } \\
\text { de Minas Ge-rais - PUC-MG }\end{array}$ & Minas/MG & Pesquisa & - & - & - \\
\hline $\begin{array}{c}\text { Universidade Presbiteria-na } \\
\text { Mackenzie }\end{array}$ & São Paulo/SP & Pesquisa & - & - & Pub. \\
\hline $\begin{array}{c}\text { Universidade Nove de Julho } \\
\text { - UNINOVE }\end{array}$ & São Paulo/SP & Pesquisa & - & - & Pub. \\
\hline
\end{tabular}


Paulo Freire na América Latina e nos Estados Unidos: vátedras e grupos de pesquisas

Quadro 11

Ações dos Grupos de Pesquisas/Paulo Freire - Diretório do CNPq (continuidade)

\begin{tabular}{|c|c|c|c|c|c|}
\hline Instituições & Local/País & & Atividade & & \\
\hline $\begin{array}{c}\text { Universidade Nove de Julho } \\
\text { - UNINOVE }\end{array}$ & São Paulo/SP & Pesquisa & - & - & Pub. \\
\hline $\begin{array}{c}\text { Universidade Federal de Santa } \\
\text { Maria - UFSM }\end{array}$ & Santa Maria/RS & Pesquisa & - & - & - \\
\hline $\begin{array}{l}\text { Universidade Federal de Juiz de } \\
\text { Fora - UFJF }\end{array}$ & Juiz de Fora/MG & Pesquisa & - & - & - \\
\hline $\begin{array}{c}\text { Universidade Federal da Paraíba } \\
\text { - UFPB }\end{array}$ & João Pessoa/ PB & Pesquisa & - & - & - \\
\hline $\begin{array}{c}\text { Universidade Federal de Pelotas } \\
\text { - UFPEL }\end{array}$ & Pelotas/RS & Pesquisa & - & - & - \\
\hline $\begin{array}{c}\text { Universidade Regional Integrada } \\
\text { do Alto Uru-guai - URI }\end{array}$ & Rio Grande do Sul & Pesquisa & - & - & - \\
\hline $\begin{array}{c}\text { Universidade Federal do Ceará } \\
\text { - UFC }\end{array}$ & Fortaleza/Ceará & Pesquisa & - & - & - \\
\hline $\begin{array}{c}\text { Universidade Federal do Ceará } \\
\text { - UFC }\end{array}$ & Fortaleza/Ceará & Pesquisa & & & \\
\hline $\begin{array}{c}\text { Universidade Federal de Pelotas } \\
\text { - UFPEL }\end{array}$ & Pelotas/RS & Pesquisa & - & - & - \\
\hline $\begin{array}{l}\text { Universidade Federal de } \\
\text { Blumenau - FURB }\end{array}$ & Blumenau/SC & Pesquisa & Ensino & - & - \\
\hline $\begin{array}{l}\text { Universidade Federal de } \\
\text { Alagoas - UFAL }\end{array}$ & Ma-ceió/Alagoas & Pesquisa & - & - & - \\
\hline $\begin{array}{l}\text { Universidade Federal do Rio } \\
\text { Grande do Norte - UFRN }\end{array}$ & Natal/RN & Pesquisa & Ensino & - & - \\
\hline $\begin{array}{l}\text { Universidade Federal do Rio } \\
\text { Grande do Norte - UFRN }\end{array}$ & Natal - RN & Pesquisa & & & \\
\hline $\begin{array}{l}\text { Universidade Federal de São } \\
\text { Paulo - UNIFESP }\end{array}$ & Santos - SP & Pesquisa & Ensino & - & - \\
\hline $\begin{array}{c}\text { Universidade Federal de Pelotas } \\
\text { - UFPEL }\end{array}$ & Pelotas - RS & Pesquisa & - & - & - \\
\hline Universidade de São Paulo - USP & São Paulo & Pesquisa & Ensino & $\begin{array}{l}\text { Ev/ } \\
\text { Cult. }\end{array}$ & \\
\hline Universidade de São Paulo - USP & São Paulo & Pesquisa & & & \\
\hline $\begin{array}{l}\text { Universidade Federal do Rio } \\
\text { Grande do Sul - UFRGS }\end{array}$ & Porto Alegre & Pesquisa & & & \\
\hline
\end{tabular}




\section{Quadro 11}

Ações dos Grupos de Pesquisa s/ Paulo Freire - Diretório do CNPq (continuidade)

\begin{tabular}{|c|c|c|l|l|c|}
\hline Instituições & Local/País & \multicolumn{3}{|c|}{ Atividades } \\
\hline $\begin{array}{c}\text { Universidade Federal de São } \\
\text { Carlos - UFS-CAR }\end{array}$ & São Carlos/SP & Pesquisa & & & Pub. \\
\hline $\begin{array}{c}\text { Universidade Federal de Minas } \\
\text { Gerais - UFMG }\end{array}$ & Minas Gerais & Pesquisa & Ensino & $\begin{array}{c}\text { Ev/ } \\
\text { Cult. }\end{array}$ & Pub. \\
\hline $\begin{array}{c}\text { Universidade Federal de Ouro } \\
\text { Preto - UFOP }\end{array}$ & Minas Gerais & Pesquisa & & $\begin{array}{c}\text { Ev/ } \\
\text { Cult. }\end{array}$ & \\
\hline
\end{tabular}

Fonte: Diretório do CNPq (2011; 2014 e 2015).

Os grupos de pesquisas evidenciam, em suas linhas de pesquisas, que a influência de Paulo Freire está presente em diferentes espaços educacionais, isto é, em escolas e sistemas públicos de ensino, prisões, hospitais, centros comunitários, entre outros espaços pedagógicos, escolares e socioeducacionais.

$\bigcirc$ pensamento educacional de Paulo Freire também vem sendo utilizado como base para diferentes estudos: políticas educacionais, formação de professores, ensino e aprendizagem, saberes docentes, práticas pedagógicas, estudos indiciários, estudos de gênero, relações étnico-raciais, educação popular, educação de jovens e adultos, educação ambiental, educação indígena, educação do campo, educação em ciências, economia solidária, movimentos sociais e populares, educação científica, educação intercultural e decolonidade, linguagem e filosofia.

Esses campos de estudos estão relacionados a questões educacionais que envolvem segmentos das classes populares excluídas socialmente, como os indígenas, a população do campo, os jovens e adultos das periferias urbanas, mulheres, negros, entre outros segmentos.

Paulo Freire está presente, ainda, em diversos campos do conhecimento: na educação, nas ciências sociais, jurídicas, agrárias, naturais, na filosofia e nas Letras.

Essa presença de Paulo Freire, nesses campos de conhecimento se dá, porque sua educação apresenta questões filosóficas, ao tratar da antropologia filosófica, da ética, da teoria do conhecimento, da estética e da política, entrecruzando com problemas dos direitos humanos; debater sobre o processo de 
alfabetização, por meio da leitura e da escrita e refletir sobre situações ambientes e socioculturais, entre outras.

Foi exatamente porque nos tornamos capazes de dizer o mundo, na medida em que o transformávamos, em que o reiventávamos, que terminamos por nos tornar ensinantes e aprendizes. Sujeitos de uma prática que se veio tornando políitica, gnosiológica, estética e ética (FREIRE, 1993, p. 19, grifo do autor).

As temáticas mais evidenciadas nas pesquisas das Cátedras, Institutos e Grupos de Estudos são:os estudos referentes ao pensamento educacional de Paulo Freire; sobre educação popular; Paulo Freire em sistemas públicos de ensino;Paulo Freire, educação e cultura;ensino e prática pedagógica. $\bigcirc$ de menor incidência é o tema Linguagem e Educação (Quadro 11 ).

Ademais, temáticas que envolvem estudos sobre o próprio Paulo Freire e sua educação em geral, por temas específicos de sua educação e na aplicabilidade de seu pensamento educacional em sistemas públicos de ensino e em práticas em diferentes contextos socioculturais.

\section{Quadro 12}

\section{Temáticas das pesquisas}

\begin{tabular}{|l|}
\hline \multicolumn{1}{|c|}{ Temáticas } \\
\hline Estudos freireanos/educação de Paulo Freire/Teoria/pensamento de Paulo Freire \\
\hline Educação popular \\
\hline Paulo Freire nos sistemas de ensino/escolas/pedagogia \\
\hline Paulo Freire, educação e cultura, diversidade, interculturalismo \\
\hline Ensino/conteúdos/metodologia/prática pedagógica \\
\hline Diálogos com Paulo Freire \\
\hline Educação latino-americana/mercosul \\
\hline Educação de jovens e adultos, Educação indígena e do campo \\
\hline Educação freireana e filosofia \\
\hline Paulo Freire e a formação de professores \\
\hline Linguagem e educação \\
\hline
\end{tabular}

Fontes: Sites e Diretório do CNPq (201 1; 2014). 
Os cursos ofertados se caracterizam por quatro tipos de formação: (1) pedagógica para professores do ensino médio e ensino superior; (2) de educadores populares; (3) de professores da Educação de Jovens e Adultos e (4) sobre a educação de Paulo Freire. Essas formações são realizadas por meio de cursos, oficinas e palestras (Quadro 12).

Nesse sentido, há uma preocupação por parte das Cátedras/ Institutos/Universidade/Grupos de realizar formação de professores visando atuar no ensino médio e superior, na educação de jovens e adultos e em práticas de educação popular, além de formar educadores de base freireana.

\section{Quadrol3}

\section{Cursos: Cátedras/Institutos/Universidade/Grupos}

\begin{tabular}{|l|}
\hline \multicolumn{1}{|c|}{ Cursos } \\
\hline Cursos de formação superior \\
\hline Círculo de Leituras Paulo Freire \\
\hline Cursos de formação de professores \\
\hline $\begin{array}{l}\text { Formação pedagógica para professores, técnicos de ensino superior e téc-nicos de } \\
\text { ensino médio }\end{array}$ \\
\hline Formação e experiências de educação popular \\
\hline Jornada de estudos Paulo Freire \\
\hline Cursos sobre a educação de Paulo Freire em diferentes níveis de ensino \\
\hline Cursos, oficinas, palestras sobre a educação de Paulo Freire \\
\hline $\begin{array}{l}\text { Cursos de formação de professores da Educação de Jovens e Adultos e Cursos de } \\
\text { Especializaçães }\end{array}$ \\
\hline Formação inicial e continuada de jovens e adultos \\
\hline Formação em educação popular, por meio de cursos, oficinas e palestras \\
\hline
\end{tabular}

Fontes: Sites e Diretório do CNPq (2011; 2014; 2015).

Todos os eventos mencionados referem-se a estudos sobre o Paulo Freire (jornadas, colóquios, seminários, etc.) - Quadro 13 
Paulo Freire na América Latina e nos Estados Unidos: vátedras e grupos de pesquisas

\section{Quadrol4}

Eventos: Cátedras/Institutos/Universidade/Grupos

\begin{tabular}{|l|}
\hline \multicolumn{1}{|c|}{ Eventos } \\
\hline Seminários e Encontros internacionais e nacionais de Paulo Freire \\
\hline Colóquios Paulo Freire \\
\hline Jornada Paulo Freire \\
\hline Fóruns Paulo Freire \\
\hline
\end{tabular}

Fontes: Sites e Diretório do CNPq (2011; 2014; 2015).

Esses eventos trazem, como foco, Paulo Freire, mas debatem não apenas o seu pensamento educacional, mas também apresentam práticas freireanas em diversos contextos socioeducacionais.

Desta forma, o pensamento educacional de Paulo Freire vem sendo debatido e refletido tanto nas formações de professores quanto em eventos e fóruns, mantendo vivo o legado da educação freireana. Amplia-se a leitura de suas obras em diferentes contextos e temas educacionais e em outros campos de conhecimento.

\section{Institutos/Grupos/Cátedras Paulo Freire nos Estados Unidos}

Nos Estados Unidos, encontram-se Institutos, Grupos de estudos, Escolas, Projetos e Programas tendo por base o pensamento socioeducacional de Paulo Freire. Diferentemente da América Latina, a referência principal é Paulo Freire e a sua obra, não estando restrita à educação.

Destaca-se, no mapeamento realizado em sites, 11 registros, sendo 01 Instituto Paulo Freire, 04 projetos, 02 escolas, 03 Programas envolvendo pedagogia do oprimido/crítica, arte e teatro e 01 Grupo de Pesquisa, em 06 Estados norte-americanos (Quadro 14). 


\section{Quadro 14 \\ $N^{\circ}$ de Registros}

\begin{tabular}{|c|c|}
\hline Denominação & Quantidade \\
\hline Instituto Paulo Freire & 01 \\
\hline Projetos Paulo Freire & 04 \\
\hline Escolas Paulo Freire & 02 \\
\hline $\begin{array}{c}\text { Programas de pedagogia do oprimido/crítica, arte } \\
\text { e teatro }\end{array}$ & 03 \\
\hline Grupo de pesquisa & 01 \\
\hline Total & 11 \\
\hline
\end{tabular}

Fonte: sites (2014; 2015).

Os Institutos, Grupos, Projetos e Programas estão vinculados às Universidades e observa-se uma escola que utiliza referencial educacional de Paulo Freire no trabalho pedagógico com adolescentes negros.

$\mathrm{Na}$ "Graduate School of Education and Information Studies" da University of Califórnia - UCLA, sediada em Los Angeles, foi criado o Instituto Paulo Freire ${ }^{2}$, dirigido por Carlos Torres, contendo vários projetos em diferentes países. O Instituto Paulo Freire é o único Instituto encontrado e o mais bem estruturado entre os sites pesquisados.

\section{Quadro 15}

Institutos, Grupos, Projetos, Escolas e Programas - Estados Unidos

\begin{tabular}{|c|c|c|}
\hline $\begin{array}{c}\text { Institu-tos/Projetos/Grupos/Escolas/ } \\
\text { Programas }\end{array}$ & Instituição & Local \\
\hline Paulo Freire Institute & University of California & Los Angeles - California \\
\hline $\begin{array}{c}\text { The Freire Project: critical, cultural, com- } \\
\text { munity, youth and media ac-tivism }\end{array}$ & $\begin{array}{c}\text { The Internacional Institute Critical } \\
\text { Pedagogy }\end{array}$ & California \\
\hline Paulo Freire democratic Project & Chapman University - California \\
\hline Paulo Freire democratic Project & $\begin{array}{c}\text { Chapman University -College of } \\
\text { Education Studies }\end{array}$ & Chicago - Illinois \\
\hline
\end{tabular}


Paulo Freire na América Latina e nos Estados Unidos: vátedras e grupos de pesquisas

\section{Quadro 15}

Institutos, Grupos, Projetos, Escolas e Programas - Estados Unidos (Continuidade)

\begin{tabular}{|c|c|c|}
\hline $\begin{array}{c}\text { Institu-tos/Projetos/Grupos/ } \\
\text { Escolas/Programas }\end{array}$ & Instituição & Local \\
\hline Critical Pedagogy \& Art & Lesley University & Cambridge, Massachusetts \\
\hline Paulo Freire Freedom School & $\begin{array}{c}\text { University Tucson - down-town } \\
\text { campus }\end{array}$ & Tucson - Arizona \\
\hline The Paulo Freire School & High School/ Secondary Teacher & Newark- New Jersey \\
\hline $\begin{array}{c}\text { Pedagogy \& theatre of oppressed } \\
\text { (PTO) }\end{array}$ & University of Nebraska Omaha & Omaha - Ne-braska \\
\hline Adult Education project & National Louis University & Chicago - Illinois \\
\hline Community Practitioners Research & California State University & California \\
\hline HutchinsSchoolof Liberal Studie & Sonoma State University & Sonoma - Cali-fornia \\
\hline
\end{tabular}

Fontes: sites (2014; 2015)

site "Freire Project: Critical Cultural Community, Youth, and Media Activism" ${ }^{3}$ abriga diversas informações sobre centros internacionais, projetos, jornais on-line que trabalham com as concepções freireanas. Nele, encontram-se trabalhos desenvolvidos nos Estados Unidos, como: Chapman Univeristy, em Orange, na Califórnia, que desenvolve o Projeto Democrático Paulo Freire $(\mathrm{PFDP})^{4}$. Esse projeto abriga uma coleção de iniciativas locais, regionais e internacionais sediadas fora do Colégio de Estudos de Educação da Universidade de Chapman, que capta a sua luta democrática para a justiça social.

O PFDP capta recursos para ajudar indivíduos, grupos e coletivos para melhorar suas escolas, comunidades e fortalecer práticas democráticas. Os docentes trabalham nas áreas de currículo, educação bilíngue, pedagogia crítica e educação de liderança.

Outras universidades encontradas, por meio do site "Paulo Freire Institute", foram: Universidade de Nebraska (University of Nebraska - Omaha - UNO), Universidade Nacional Lovis (National Lovis University), Universidade Estadual da Califórnia (California State University) e Universidade Estadual de Sonoma (Sonoma State University).

Na década de 1930, a Universidade de Nebraska, em Omaha adotou programas de educação de adultos e educação continuada, debatendo sobre a aprendizagem ao longo da vida. Por meio de Doug Paterson, vem 
realizando há mais de 20 anos o trabalho com Augusto Boal e seu Teatro do Oprimido.

A Universidade Nacional Louis de Chicago realiza pesquisas e práticas relacionadas à educação de adultos.

Na pesquisa sobre a Universidade Estadual da Califórnia |California State Universityl ${ }^{5}$, que já foi citado pelo Instituto Paulo Freire como centro internacional da ideologia freireana, identificaram-se informações apenas sobre a Comunidade Praticantes de Pesquisa. Essa comunidade utiliza alguns princípios freireanos, embora não mencione o nome do educador, visto que buscam perceber as necessidades dos alunos, considerando suas raízes étnicas.

A Universidade Estadual Sonoma (Sonoma State University) encontra-se no estado da Califórnia. A filosofia, subjacente ao corpo docente e programas na Faculdade de Educação da universidade, é de justiça social e de responsabilidade individual com relação à educação de crianças e jovens em uma sociedade democrática multicultural. Permeiam a filosofia da universidade os ideais de John Dewey, Paulo Freire, Lev Vygotsky, entre outros renomados educadores.

Esses Institutos, grupos e projetos desenvolvem: ensino, pesquisa, eventos e publicação (04); Ensino, teatro, artes, publicação e eventos (02); Ensino, teatro, artes e eventos $(01)$; Pesquisa e publicação (01); Ensino e eventos (01); Ensino e pesquisa (01); Ensino e publicação (01).

\section{Quadro 16}

\section{Ações dos Institutos, Grupos e Projetos - Estados Unidos}

\begin{tabular}{|l|l|}
\hline \multicolumn{1}{|c|}{ Instituto/Grupos/Projetos } & \multicolumn{1}{c|}{ Atividades } \\
\hline Paulo Freire Institute & Pesquisa, ensino, eventos, publicação. \\
\hline $\begin{array}{l}\text { The Freire Projetc: critical, cultural, community, } \\
\text { youth and media ac-tivism }\end{array}$ & Pesquisa, eventos, ensino, publicação \\
\hline Paulo Freire democratic Project - Orange & Pesquisa, ensino, eventos e publicações \\
\hline Paulo Freire democratic Project - Chicago & Pesquisa, ensino, eventos e publicações \\
\hline Pedagogia Crítica e Arte & Ensino, evento, arte e publicação \\
\hline Paulo Freire Freedom Scholl & Ensino e eventos \\
\hline The Paulo Freire School & Ensino e pesquisa \\
\hline Pedagogy \& theatre of oppressed (PTO) & Ensino, teatro, publicação e eventos \\
\hline
\end{tabular}


Paulo Freire na América Latina e nos Estados Unidos: vátedras e grupos de pesquisas

\section{Quadro 16}

Ações dos Institutos, Grupos e Projetos - Estados Unidos (Continuidade)

\begin{tabular}{|l|l|}
\hline \multicolumn{1}{|c|}{ Instituto/Grupos/Projetos } & \multicolumn{1}{c|}{ Atividades } \\
\hline Adult Education project & Ensino e publicação \\
\hline Community Practitioners Research & Pesquisa e publicação \\
\hline Hutchins Schoolof Liberal Studie & Ensino, teatro, artes e eventos \\
\hline
\end{tabular}

Fonte: Sites (2015).

As atividades de ensino estão relacionadas à Educação de Jovens e Adultos, Educação popular, Formação de professor, ensino fundamental e produção de material curricular e formação em artes. Diferentemente da América Latina, há uma preocupação em relação ao ensino com a formação em artes e com o currículo escolar.

As pesquisas envolvem as seguintes temáticas: Educação popular; Formação do educador; Inclusão e justiça social; Imigração; Educação e globalização; Ecopedagogia; Pedagogia Crítica; Pedagogia do Oprimido, Estudos de Paulo Freire; Justiça social e desenvolvimento sustentável, teatro do oprimido, entre outras.

Em termos de pesquisas, também se diferenciam dos grupos de pesquisa latino-americanos ao focarem na inclusão e justiça social, em problemas da imigração, ecopedagogia e da globalização, além do teatro e da pedagogia do oprimido. Destaca-se, no contexto norte-americano, a influência de Paulo Freire na Pedagogia Crítica de Henry Giroux e Carlos Alberto Torres; na educação crítica e multicultural de Peter MacLaren e na Educação de Jovens e Adultos de Myles Horton.

Giroux (1998) afirma que o trabalho de Paulo Freire tem sido referência para o pensamento crítico, pedagogia dialógica ou alfabetização crítica em diversas partes do mundo. E Nóvoa (1998, p. 179) destaca que Freire nos Estados Unidos "[...] constitui-se em uma referência importante dos grupos de intelectuais do meio universitário, cuja agenda política incluía as questões de classe, de raça e de gênero".

O próprio Paulo Freire (1998) destaca que educadores como Henry Giroux, Peter MacLaren, Ira Shör, Carlos Alberto Torres, Donaldo Macedo, entre outros, buscaram reinventar o seu trabalho e pesquisas sobre alfabetização e pedagogia para serem aplicados nas lutas pela libertação em diversos 
espaços entre os quais as escolas e as universidades dos Estados Unidos. Ressalta, também, as tentativas de educadoras feministas em repensar a sua obra, por meio de lutas envolvendo questões de gênero e étnicas.

McLaren explica como Paulo Freire está presente em suas produções:

Eu simplesmente tentei integrar pensadores norte-americanos mais contemporâneos a essa mistura - teóricos feministas e multiculturalistas, muitos deles da comunidade intelectual afro-americana e latino-americana. Comecei a incorporar Gramsci e muitos dos pensadores marxistas ocidentais (por exemplo, da Escola de Frankfurt) em meu trabalho. Claro a tradição do pensamento indígena por todas as Américas foi - e ainda é - extremamente importante. E Freire foi sempre fundamental para o desenvolvimento de minha pedagogia crítica (McLAREN, 2007, p.01).

Em termos dos eventos, encontram-se aqueles direcionados para o debate em relação ao pensamento educacional de Paulo Freire, como o Internacional Encontro do Fórum Paulo Freire e outros voltados para a sua obra como pedagogia e teatro do oprimido.

Diferentemente da América Latina, a publicação de jornais está presente de forma significativa nos Institutos/Grupos/Projetos/Escolas e Programas dos Estados Unidos, existindo, desta forma, destaque para a publicação em forma de jornais e de artigos de e sobre Paulo Freire.

\section{Quadro 17}

\section{Publicações}

\begin{tabular}{|c|}
\hline Jornal on line Freire \\
\hline Jornal de Educação Popular \\
\hline Pedagogia e Teatro do Oprimido Jornal Internacional \\
\hline Journal of Pedagogy \\
\hline Pluralism and Practice \\
\hline Digital Commons @ UNO \\
\hline Exchanges: the on-line journal of teaching and learning in the CSU. \\
\hline Artigos freireanos \\
\hline Livros de Paulo Freire \\
\hline Livros sobre Paulo Freire \\
\hline
\end{tabular}

Fonte: Sites (2015). 
Localizada em Cambridge, a Universidade Centenária de Lesley ${ }^{6}$ mantém um Journal on line ativo: "Journal of Pedagogy, Pluralism and Practice". Há um volume publicado, em 1997, dedicado ao educador Paulo Freire, o qual proferiu uma palestra nessa universidade em abril de 1997, um mês antes de seu falecimento. Há outras publicações que referenciam Paulo Freire no ano de 2013 e 2014 no Journal. Existem, também, vários artigos que tratam de direitos civis de grupos minoritários, a exemplo das mulheres negras. $\bigcirc$ jornal trabalha bastante a questão das lutas sociais. Em geral, sua publicação é anual.

A universidade de Nebraska, em Omaha, possui um jornal chamado "Digital Commons@ UNO"7,no qual são publicados vários artigos, entre eles, muitos relacionados às obras e pensamento educacional de Paulo Freire, inclusive de outras universidades.

A Comunidade Praticante de Pesquisa mantém um Jornal chamado "Exchanges: the on-line journal of teaching and learning in the CSU". Nesse jornal, há alguns artigos relacionados à pedagogia crítica e à educação de Paulo Freire. O Jornal foi criado pelo Instituto de Ensino e Aprendizagem.

Assim, Paulo Freire nos Estados Unidos tem sido referência a práticas educacionais, principalmente em Universidades norte-americanas, e está presente em formações, eventos e publicações por meio de projetos educacionais e grupos de pesquisas.

\section{Considerações finais}

A presença de Paulo Freire, no contexto latino-americano, é significativa por meio dos Institutos, Cátedras, Grupos de Pesquisas e, também, Universidade. Em termos de grupos de pesquisas, a concentração das informações está no Brasil, considerando a existência do Diretório do CNPq, que facilita o acesso às informações.

No Brasil, há um crescimento tanto de Cátedras quanto de Grupos de Pesquisas, bem como de Redes em níveis nacionais e internacionais. Entretanto, a maioria dos Grupos e Cátedras estão concentradas na região Sudeste. Não há registro de Cátedras e de grupo de pesquisa no CentroOeste. Identificou-se, também, que não há distinção entre as atividades de Institutos e Cátedras, porque ambos desenvolvem atividades similares, ensino, 
pesquisa, extensão e publicações. Conforme as características das Instituições, podem desenvolver somente extensão ou somente ensino ou somente pesquisa, mas a maioria trabalha com mais de uma atividade.

Apesar da diversidade de ações, a pesquisa constitui uma referência. Há uma preocupação em se estudar a educação de Paulo Freire e, também, de socializar suas ideias por meio de eventos.

Um diferencial observado nos grupos de estudos dos Estados Unidos em relação aos da América Latina são as denominações utilizadas entre as quais: projetos, grupos de estudos e instituto, além de terem como um dos principais focos a publicação em jornais e revistas. Há a presença de Paulo Freire em diversos campos do conhecimento: ciências sociais, jurídicas, agrárias, naturais, educação, filosofia, letras, entre outras, mas predomina na Educação.

Nos Estados Unidos, a presença de Paulo Freire se verifica em Institutos, Grupos de estudos e projetos, sendo mencionados pelo Freire e suas obras, principalmente a pedagogia crítica e a pedagogia do oprimido. Além da educação, destaca-se a presença na arte e teatro do oprimido.

Predominam nos Estados Unidos, as atividades de pesquisa, ensino, eventos e, sobretudo, a publicação em forma de jornais e revistas

Apesar de menor o número de registros encontrados nos Estados Unidos do que na América Latina, é possível identificar a presença de Paulo Freire principalmente na dimensão crítica e libertadora de sua pedagogia.

Assim, este estudo identificou a presença de Paulo Freire na América Latina e nos Estados Unidos por meio de Instituto, Cátedras, Grupos de Pesquisas, projetos e universidades, nos quais são realizadas atividades de pesquisas sobre diferentes temáticas educacionais, o ensino, por meio de cursos de formação, publicações, veiculadas em livros, periódicos e jornais, e eventos e atividades culturais. Isso evidencia tanto a importância de sua educação quanto o fato de que Paulo Freire deixou um legado educacional que se encontra em diferentes partes do mundo, caracterizando-o como intelectual sem fronteiras, como intelectual do mundo.

\section{Notas}

1 Sem a inclusão dos Grupos de Pesquisas do CNPq. 
Paulo Freire na América Latina e nos Estados Unidos: vátedras e grupos de pesquisas

2 Informações obtidas no site do Instituto Paulo Freire. Disponível em: http://www. paulofreireinstitute.org/ Acesso em: 6 abr, 2015.

3 Freire Project: Critical Cultural Community, Youth, and Media ActivismDados disponíveis em: http://www.freireproject.org/. Acesso em: 24 abr. 2015.

4 Projeto Democrático Paulo Freire (PFDP). Dadosdisponíveis em: http://www.chapman.edu/ces/ research/paulo-freire/index.aspx. Acesso em: 20 abr. 2015.

5 California State University. Informaçõesdisponíveis em: http://www.calstate.edu/. Acesso em: 24 abr. 2015

6 Universidade Centenária de Lesley. Informações disponíveis em: http://www.lesley.edu/journal-pedagogy-pluralism-practice/1997fall/2terms=paulo\%20freire. Acesso em: 20 abr. 2015.

7 Jornal Digital Commons@UNO. Informações disponíveis em:http://digitalcommons.unomaha. edu/slcehighered/98/. Acesso em: 20 abr. 2015

\section{Referências}

FREIRE, Paulo. Prefácio da Edição em Língua Inglesa de Paulo Freire: A Critical Encounter. In: MACLAREN, Peter; LEONARD, Peter; GADOTTI, Moacir (Org.). Paulo Freire: poder, desejo e memórias da libertação. Porło Alegre: ArtMed, 1998.

Política e educação. 5. Ed. São Paulo: Cortez, 1993.

GADOTTI, Moacir (Org.). Paulo Freire: uma biobibliografia. São Paulo: Cortez, 1996.

GIROUX, Henry. Paulo Freire e a Política do Pós-Colonialismo. In: MACLAREN, Peter; LEONARD, Peter; GADOTTI, Moacir (organizadores). Paulo Freire: poder, desejo e memórias da libertação. Porło Alegre: ArtMed, 1998.

MAcLAREN, Peter. Paulo Freire é o mais importante educador crítico lido nos EUA. Revista do Instituto Humanitas Unisinos, v. 7, n. 223, jun. 2007. Disponível em: http://www. ihuonline.unisinos.br. Acesso em: 14 ago. 2013.

MAcLAREN, Peter. Uma pedagogia da possibilidade: reflexões sobre a política educacional de Paulo Freire. In: FREIRE, Ana Maria Araújo (Org.); OLIVEIRA, Ivanilde Apoluceno de; MACHADO, Roberto (Col.) A Pedagogia da Libertação em Paulo Freire. São Paulo: UNESP, 2001.

MAFRA, Jason; GADOTTI, Moacir. UNIFREIRE: Universitas Paulo Freire /Comunidades freirianas no mundo). São Paulo: Instituto Paulo Freire, 2005. Disponível em: www. paulofreire.org. Acesso em: 2 jun. 2014. 
OLIVEIRA, Ivanilde Apoluceno de; MOTA NETO, João Colares. A construção de categorias de análise na pesquisa em educação. In: Abordagens teóricas e construções metodológicas na pesquisa em educação. Belém: EDUEPA, 2011.

NÓVOA, António. Paulo Freire (1921-1997): a "inteireza" de um pedagogo utópico. In: APPLE, Michael W.; NÓVOA, António (Org.). Paulo Freire: política e pedagogia. Portugal: Porto Editora, 1998.

Prof ${ }^{a} \mathrm{Dr}^{a}$ Ivanilde Apoluceno de Oliveira Universidade do Estado do Pará Departamento de Filosofia e Ciências Sociais Coordenadora do Programa de Pós-Graduação em Educação Núcleo de Educação Popular Paulo Freire (CNPq-UEPA) E-mail| ivanilde.apoluceno@pq.cnpq.br Profa ${ }^{a} r^{a}$ Tânia Regina Lobato dos Santos Universidade do Estado do Pará Departamento de Educação Geral

Vice-Coordenadora do Programa de Pós-Graduação em Educação Núcleo de Educação Popular Paulo Freire (CNPq-UEPA) E-mail | tanialobato@superig.com.br

Recebido 22 mar. 2018 Aceito 22 maio 2018 